\title{
College Students Attitude toward Elderly Persons after Aging Simulation Experience
}

\author{
Seung youn Hong* \\ Department of Senior Industry, Kangnam University, South Korea
}

Received: November 10, 2017; Published: November 28, 2017

*Corresponding author: Seung youn Hong, Department of Senior Industry, Kangnam University, Yongin, South Korea, Tel: 811087994185;

Email: Yoni91@hotmail.com

\begin{abstract}
Objective: To evaluate the impact of the Aging simulation experience on students' attitudes towards the elderly.

Method: One hundred fifty six college students (mean age: 22.74) were recruited and were assigned either experiment group (EG) or control group (CG). Students in EG were dressed in an aging simulation suits(SAKAMOTO) and wore Aging simulation glasses (GERT, Germany), which transformed students into a frail senior citizen, suffering from weaken muscle, impaired vision, hearing loss, kyphosis and joint stiffness. With aging simulation suits, students performed daily activities for 2 hours in three sessions in 5 areas which include a bedroom, living room, bathroom, kitchen and dining room. Then they went outside to experience real life such as taking public transportations, going for grocery shopping, watching movies, etc. for another two sessions. Student's attitudes toward older adults were measured with the Ageing Semantic Differential before and after the intervention.
\end{abstract}

Results: There was a statistically significant improved in attitude in EG towards the elderly following four weeks of the aging simulation program. Attitude toward seniors in EG was significantly positively changed $(\mathrm{t}=2.47, \mathrm{p}<.05)$ while that of CG was negatively changed. All three subscales--"Instrument-ineffective", "Autonomous-dependent" and "Personal acceptability-unacceptability turned significantly positive after the experience.

Keywords: Aging simulation; Attitude; Students; ASD

\section{Introduction}

The aging speed of South Korea is apparently faster than that of developed countries; The percentage of individuals over 65 years is predicted $38 \%$ in 2050 (National Statistical Office, 2017). As this rapid aging phenomenon, one of the critical challenges is to prepare our future workforce to care for seniors in this enlargement and unique group. Attitudes have long been associated with behavior. The theory of planned behavior Ajzen [1] suggests a causal relationship between attitudes, intention and behavior. According to the theory, attitude towards particular population, such as older adults, will affect intentions, which eventually behavior toward them. Positive attitude toward older adults leads a favorable behavior and actions. A more personalized learning may allow students to develop their own beliefs, values, and attitudes based on their own experience and reflections.

There has been considerable research examining student attitudes to aging, the majority focusing on nursing and medical students Jeong, Lucchetti, Lucchetti, Douglass [2-4]. Researchers have reported significant improvement in participants' empathy and attitude towards in the health care system after integrating an aging simulation game. However, only limited number of studies applies this on students from other service professions [5-9]. Therefore, the purpose of the present study was to examine whether the Aging simulation experience would cause more positive attitudes toward the aged in the general college students.

\section{Materials and Methods}

Subjects: One hundred fifty-six students were assigned either the experimental group (EG) or the control group (CG). EG participated in aging simulation program for six times, while CG attended the basic introduction of social work.

Aging simulation program: The aging simulation program was conducted for four times a month at the KN University Aging simulation center. Students wore aging simulation suits and glasses and performed daily activities for 3 hours in three sessions at the five areas of the center including a bedroom, living room, bathroom, kitchen and dining room. Then they performed the two-hour particular activity at the community level such as using a public transportation either bus or subway, going to grocery shopping, visiting the public library, and going to movie theater, etc. Aging simulation suit (Sakamoto Co., Japan) (Figure 1) used weights and straps to resists movement to mimic the effect of muscle loss and 
limit dexterity of the students to make everyday tasks difficult. Aging simulation glasses (GERT, Germany) simulate six different eye disease including macular degeneration, unilateral retinal detachment, cataract, diabetic retinopathy, glaucoma and retinitis Table 1: Aging simulation program content and procedure. pimentos (Figure 1). Students had the aging simulation experience guided by a principal investigator and six trained staff members. The contents and the order of the aging simulation program were presented as in (Table 1).

\begin{tabular}{|c|c|c|}
\hline Level & Procedure & Program content \\
\hline \multirow{4}{*}{ Center level } & 1. Bed room & Making a bed, Lying in bed, Dress, Putting on socks \\
\cline { 2 - 3 } & 2. Bath room & Sitting the toilet, Washing face, Brushing teeth, Brushing hair, Getting into the bathtub, Taking shower \\
\cline { 2 - 3 } & 3. Living room & $\begin{array}{c}\text { Timing Pegboard, Reading script with six different aging glasses on, Going up and down the stairs, Sitting the } \\
\text { chair }\end{array}$ \\
\cline { 2 - 3 } & 4. Kitchen & Using chopsticks, Moving beans, preparing meals, Laundry \\
\cline { 2 - 3 } & 5. Hallway & Picking up four scarves, sweeping with broom, Wiping floor with cloth, Time to up and go \\
\hline Community level & & $\begin{array}{c}\text { Public transportation (i.e., bus, subway), Watching movie, stopping by post office, public document, Grocery } \\
\text { shopping, Reading at the library, etc }\end{array}$ \\
\hline
\end{tabular}

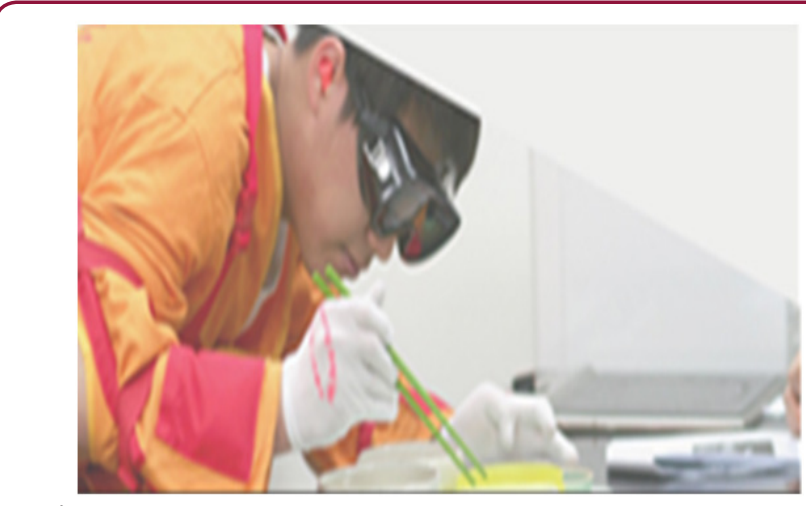

Figure 1: Aging experience.

Measures: The Ageing Semantic Differential (ASD) were administered to measure if aging simulation experience change students attitudes toward older adult. The ASD was developed by Sanders, Montgomery, Pittman and Balk well (1984) and had permission for utilizing for a research by the author. The ASD consists of 20 -item that assess the attitudes or perceptual predisposition of students towards older adults. Each item consisted of bipolar adjective reflecting extremes of words that are used to described elderly persons with a response range of 1-7, for example wise (1) to foolish (7). A score between one and three represents a more positive attitude toward older adults (they are wiser than foolish), a score of four represents a neutral response (neither wise nor foolish), and a score five to seven represents a negative attitude towards older adults (they are more foolish than wise). The lower ASD score indicates a more positive view of older adults. The ASD can be broken down into the subgroup "Instrument-Ineffective," "Autonomous Dependent," and "Personal Acceptability-Unacceptability." The validity and reliability of the original ASD was Cronbach's alpha 0.96, and the Cronbach's alpha in the present study was 0.931 indicating a high degree of internal consistency for the overall scale.

Table 2: ASD scores pre- and post-aging simulation experience.
Statistical analysis: Data analysis was conducted using SPSS version 21.0 (IBM, Chicago, IL, USA). Students provide a unique ID code that enables their pre- and post-scores to be matched for analysis. Students who completed both pre- and post- scores to be matched for analysis were included. Descriptive statistics were used to summarize the quantitative data. Homogeneity between the groups was analyzed using a t-test, and Fisher's exact test. Paired t-test and t-test was adopted for testing changes of attitudes toward the elderly.

\section{Results}

Demographics: In total 156 students completed pre- and postASD survey and emphasize survey (response rate 93\%) allowing them to be matched. Sixty-seven percent of students were female and $33 \%$ male with mean age of 22.74 . Twenty-eight percent of students were the freshman, $33 \%$ sophomore, $25.6 \%$ junior and last of them are senior. The majority (62.8\%) of the respondents had ever lived with elderly persons, and only $8.3 \%$ of the respondents live with parents and grandparents in the present. $62.8 \%$ reported they had felt and experienced that the society turned to the aging community.

Ageing Semantic Differences: The mean total score of 20 items on the ASD survey pre-test in EG was 78.17, which decreased significantly post-test to $74.81(\mathrm{t}=2.467, \mathrm{p}=.016)$, indicating on average students' attitudes become increasingly positive toward older adults (Table 2). In contrast, a total score of ASD in CG was increased (Table 2). Three subscales on the ASD changed significantly from pre- to post-test. "Instrument-ineffective" scores in EG significantly decreased from 44.62 to $42.86(\mathrm{p}<.048)$ in contrast to significantly increase in CG. "Autonomous-dependent" scores in both EG and CG significantly decreased ( $p<.001)$, and "Personal acceptability-unacceptability" scores in EG decreased from 14.60 to 13.45 ( $\mathrm{p}=0.007$ ) in contrast to unchanged in CG.

\begin{tabular}{|c|c|c|c|c|c|c|}
\hline & \multicolumn{3}{|c|}{ Mean (SD) EG } & \multicolumn{2}{c|}{ Mean (SD) CG } \\
\hline ASD subscale & Pre & Post & Change & Pre & Post & Change \\
\hline Instrument-Ineffective (10 items) & $44.62(8.24)$ & $42.86(8.91)$ & $1.76\left(8.10^{*}\right)$ & $43.25(10.52)$ & $44.91(8.95)$ & $-1.67^{*}$ \\
\hline Autonomous-Dependent $(\mathrm{n}=6)$ & $26.02(5.92)$ & $18.50(4.79)$ & $7.52\left(4.35^{* *}\right)$ & $27.36(7.87)$ & $20.77(5.85)$ & $6.59^{* *}$ \\
\hline
\end{tabular}




\begin{tabular}{|c|c|c|c|c|c|c|}
\hline Personal acceptability- unacceptability $(\mathrm{n}=4)$ & $14.60(3.84)$ & $13.45(3.95)$ & $1.15\left(3.84^{* *}\right)$ & $14.73(4.33)$ & $15.13(4.38)$ & -0.4 \\
\hline Total $(20$ items) & $78.17(14.09)$ & $74.81(15.38)$ & $3.36\left(12.63^{*}\right)$ & $78.19(19.24)$ & $80.81(17.24)$ & -2.628 \\
\hline
\end{tabular}

${ }^{*} \mathrm{p}<.05,{ }^{* *} \mathrm{p}<.001$

\section{Discussion}

The quasi-experimental study investigated the effect of aging simulation experience on college students' attitude towards the older adults. In results, aging simulation experience positively influences college student's attitude and gave a meaningful learning opportunity to understand the physiological changes with aging. These opportunities provide the students with a greater understanding of each professional's role and their role in the aged community. With the super-aging society's approaches, there is need to develop the Aging simulation experience as the 101 curricula in the university.

\section{References}

1. Ajzen I (1991) The theory of planned behavior. Organizational behavior and human decision processes 50(2): 179-211.

2. Douglass Carolinda, Henry, Beverly W, Kostiwa, Irene M (2008) An aging game simulation activity for allied health students. Educational Gerontology 34(2): 124-135.

3. Chen AM, Kiersma ME, Yehle KS, Plake KS (2015) Impact of an aging simulation game on pharmacy students' empathy for older adults. American journal of pharmaceutical education 79(5): 65-71.
4. Jeong H, Lee Y, Hyuksoo Kwon (2017) Effects of Senior Simulation Program for Nursing Students: An integrated Study in South Korea. Eurasia Journal of Mathematics, Science and Technology Education 13(8): 4437-4447.

5. Lucchetti AL, Lucchetti G, de Oliveira IN, Moreira-Almeida A, Da Silva Ezequiel (2017) Experiencing aging or demystifying myths?-impact of different geriatrics and gerontology teaching strategies in first year medical students. BMC medical education 17(1): 35.

6. Chug K (1998) Aging and Social Welfare Policies: Health Care and Income Maintenance Programs. Paper presented at the UNFPA Conference Seoul.

7. (2009) Joint Health Surveys Unit (National Centre for Social Research and UCL Department of Epidemiology and Public Health). Health Survey for England-2008: Physical Activity Fitness, The NHS Information Centre, Leeds, UK.

8. (2017) National Statistical Office, Aging statistics.

9. Gregory F Sanders, James E Montgomery, Joe F Pittman, Carolyn Balk well (1984) Youth's attitudes toward the elderly. Journal of Applied Gerontology 3(1): 59-70.

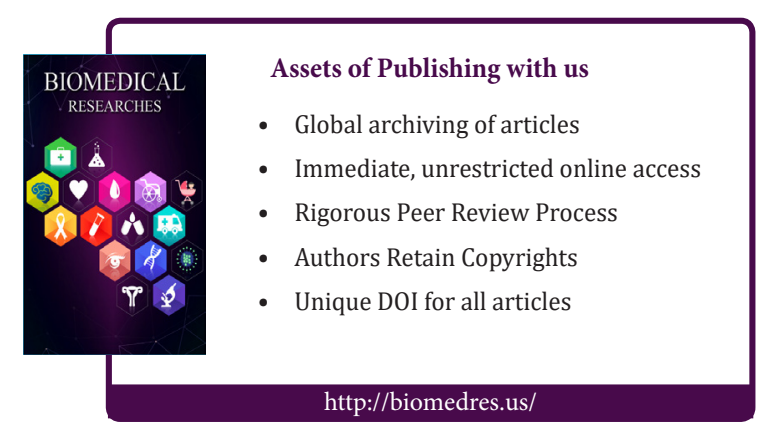

